\title{
A new suturing procedure for closure of a gastrocutaneous fistula
}

Gastrostomy is a useful technique for feeding patients. Gastrostomy tubes are removed when patients recover an acceptable nutritional status and can eat again. Usually, the puncture site closes spontaneously in a short time; however, in some cases, a gastrocutaneous fistula can persist and may affect the patient's quality of life. Different closure techniques are available, such as clip placement, with or without electrochemical cautery [1], use of biological fibrin glue [2], or complex percutaneous endoscopic suturing [3]. We have developed a novel and easier suturing procedure for closure of a gastrocutaneous fistula.

A 60-year-old man was treated with chemoradiotherapy for a tumor of the tonsil. Gastrostomy feeding was planned along with this, with introduction of a feeding tube using a classical surgical procedure prior to his anticancer treatment. Enteral feeding was continued throughout his oncologic treatment and until 1 year after the end of his chemoradiotherapy, because of side effects and ongoing difficulties swallowing. As is more often the case after a surgical procedure, the puncture site did not close after removal of the tube. The resulting gastrocutaneous fistula was associated with skin irritation, pain, and therefore a poorer quality of life. First, we unsuccessfully attempted closure with a technique that used biological fibrin glue [2]. We then offered the patient a newly developed percutaneous endoscopic suturing procedure using a doubleneedle gastropexy device ( $\bullet$ Fig. 1 ) from a gastrostomy kit (Freka-Pexat, 15 Fr; Fresenius Kabi, Bad Homburg, Germany) [4]. At endoscopy, a loop was inserted through needle 1 ; then a second suture thread (we used polydioxanone [PDS] plus antibacterial silk threads of diameter 1 ) was inserted through needle 2 and passed through this loop. As a result, by crossing the two suture threads within the one process, we were able to suture the gastric wall to the anterior abdominal wall and incorporate the fistula within the stitches. ( Fig. 2; Video 1)

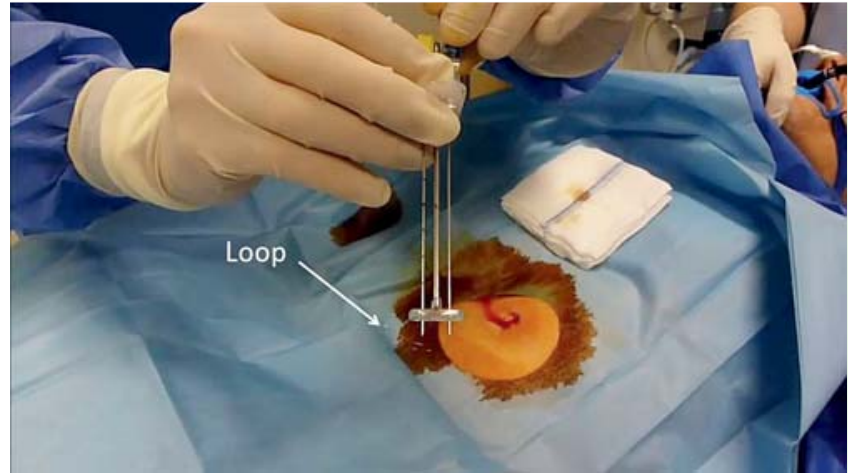

Fig. 1 The doubleneedle gastropexy device and preloaded suture loop.

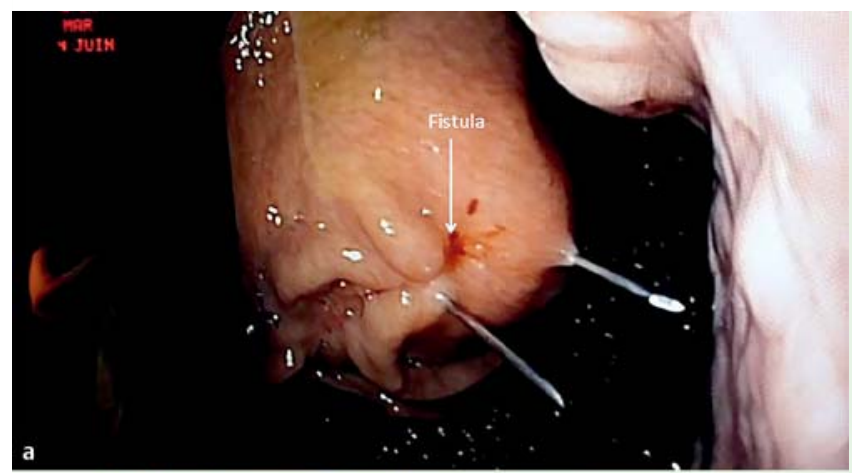

Fig. 2 Endoscopic images showing: a the two puncture points on either side of the fistula as the first suture is created; b the nylon thread being introduced via needle 2 and crossing through the loop of thread that had been previously introduced

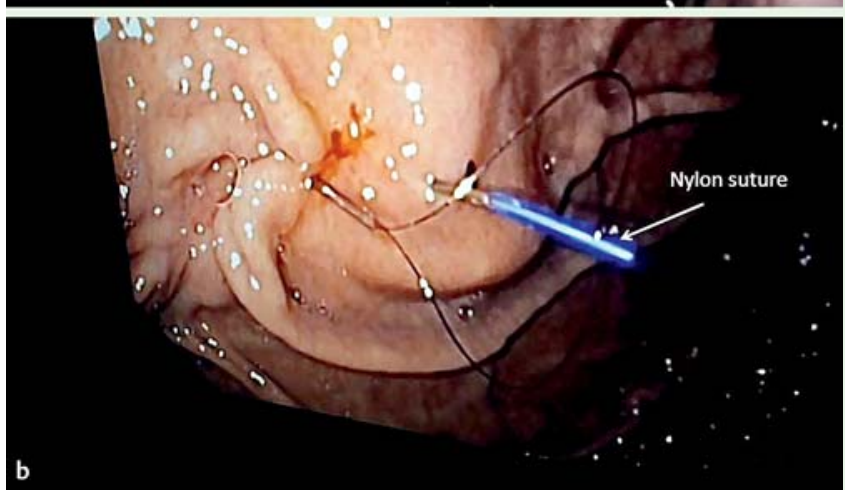
through needle 1 .

We did not commence the patient on a proton pump inhibitor. The stitches were removed after 3 weeks, and when he was examined 3 months later, the patient's fistula had closed correctly and he had had no further symptoms.

\section{Endoscopy_UCTN_Code_TTT_1AO_2AI}

Competing interests: None

\section{Video 1}

Percutaneous endoscopic suturing procedure using a double-needle gastropexy device showing: the double-needle gastropexy device with preloaded loop; the punctures being made on either side of the fistula; endoscopic views of the sutures, with the introduction of the preloaded loop through needle 1, then the introduction of the nylon thread through needle 2 , which is passed through the first suture loop; and the two sutures forming a cross to incorporate and close the fistula as the gastric wall is tethered to the anterior abdominal wall. 
Nicolas Flori' ${ }^{1}$, Julie Courraud', Eric Assenat ${ }^{1}$, Pierre Senesse ${ }^{1,2,3}$

${ }^{1}$ Department of Clinical Nutrition and Gastroenterology, Institut régional du Cancer de Montpellier (ICM), Montpellier, France

2 SIRIC Montpellier Cancer, Institut régional du Cancer de Montpellier (ICM), Montpellier, France

${ }^{3}$ Laboratory Epsylon, EA 4556 Dynamics of Human Abilities \& Health Behaviors, University of Montpellier, France

\section{References}

1 Kothari TH, Haber G, Sonpal $N$ et al. The overthe-scope clip system - a novel technique for gastrocutaneous fistula closure: the first North American experience. Can J Gastroenterol 2012; 26: 193 - 195

2 Papavramidis ST, Eleftheriadis EE, Papavramidis TS et al. Endoscopic management of gastrocutaneous fistula after bariatric surgery by using a fibrin sealant. Gastrointest Endosc 2004; 59: 296 - 300

3 Eskaros S, Ghevariya V, Krishnaiah $M$ et al. Percutaneous endoscopic suturing: an effective treatment for gastrocutaneous fistula. Gastrointest Endosc 2009; 70: 768 - 771

4 Shastri YM, Hoepffner N, Tessmer A et al. New introducer PEG gastropexy does not require prophylactic antibiotics: multicenter prospective randomized double-blind placebocontrolled study. Gastrointest Endosc 2008; 67: $620-628$

\section{Bibliography}

Dol http://dx.doi.org/

10.1055/s-0034-1365433

Endoscopy 2014; 46: E258-E259

(c) Georg Thieme Verlag KG

Stuttgart · New York

ISSN 0013-726X

\section{Corresponding author}

\section{Pierre Senesse, MD, PhD}

Institut régional du Cancer - Montpellier (ICM)

Department of Clinical Nutrition

and Gastroenterology

Parc Euromédecine

34298 Montpellier cedex 5

France

Fax: +33-467-613729

pierre.senesse@icm.unicancer.fr 